Article

\title{
Proximate Composition, Extraction, and Purification of Theobromine from Cacao Pod Husk (Theobroma Cacao L.)
}

\author{
Van Tang Nguyen ${ }^{1,2, *}$ and Nghia Huu Nguyen ${ }^{3}$ \\ 1 School of Environmental and Life Sciences, Faculty of Science and Information Technology, \\ University of Newcastle, Ourimbah, NSW 2258, Australia \\ 2 Department of Food Technology, Faculty of Food Technology, Nha Trang University, \\ No. 2 Nguyen Dinh Chieu, Nha Trang, Khanh Hoa 8458, Vietnam \\ 3 Department of Thermal and Refrigeration Technology, Faculty of Mechanical Engineering, \\ Nha Trang University, No. 2 Nguyen Dinh Chieu, Nha Trang, Khanh Hoa 8458, Vietnam; \\ huunghiaktl@gmail.com \\ * Correspondence: vantang.nguyen@uon.edu.au; Tel.: +61-4-3423-8842
}

Academic Editor: Manoj Gupta

Received: 4 March 2017; Accepted: 30 March 2017; Published: 2 April 2017

\begin{abstract}
The aims of this study were to determine the proximate composition of cacao pod husk as well as the optimal conditions for extraction and purification of theobromine from cacao pod husk. The results indicated that cacao pod husk had high contents of moisture and carbohydrate $(87.06 \%$ and $11.03 \%$ by fresh weight, respectively), but low contents of crude protein, crude lipid, and ash $(0.31 \%$, $0.12 \%$, and $1.48 \%$ by fresh weight, respectively). The optimal conditions for extraction of theobromine from cacao pod husk were of $70 \%$ ethanol, with an extraction time of $90 \mathrm{~min}$, and 1 as the number of extractions. A concentration of $10 \%$ by volume of $10 \%$ lead acetate solution was the best selection for purification of the crude extracts containing theobromine from cacao pod husk. Under these optimal conditions, theobromine content obtained from cacao pod husk was $6.79 \mathrm{mg} / 100 \mathrm{~g}$ dry weight. The finding from this study is a valuable contribution for obtaining theobromine from an abundant, inexpensive, renewable, and sustainable source for potential application in the nutraceutical, medical, and pharmaceutical industries.
\end{abstract}

Keywords: cacao pod husk; theobromine; proximate composition; extraction; purification

\section{Introduction}

Theobroma cacao L. has been known as "the food of the gods". Cacao tree is wildly grown in tropical and subtropical areas around the world including in Africa, such as Côte d'Ivoire, Ghana, Nigeria, and Cameroon, in American countries, like Brazil, Ecuador, Columbia, and Mexico, in Caribbean and Southwestern Pacific countries, such as the Dominican Republic and Papua New Guinea, and in Southeast Asian countries, like Indonesia, Malaysia, and Vietnam. Total production of cacao bean is estimated worldwide to be approximately 4.0 million tonnes in 2013, with a value about $\$ 12$ billion [1]. Residues or wastes from the cacao processing industry consist of cacao pod shell, husk, pulp/mucilage, and hull, which account for a high proportion, approximately $85 \%$ by fresh weight of total cacao pod mass [2], in which the annual worldwide amount of cacao pod husk is estimated to be about 55 million tonnes, which is equal to 13 times the total amount of cacao bean. Therefore, cacao pod husk needs to be exploited to produce high-value-added products and this waste has been considered as an abundant, inexpensive, and renewable source of theobromine, a valuable compound, which exhibits stimulatory effects on the central nervous, gastrointestinal, cardiovascular, renal, and respiratory systems [3]. The chemical structure of theobromine is shown in Figure 1. 


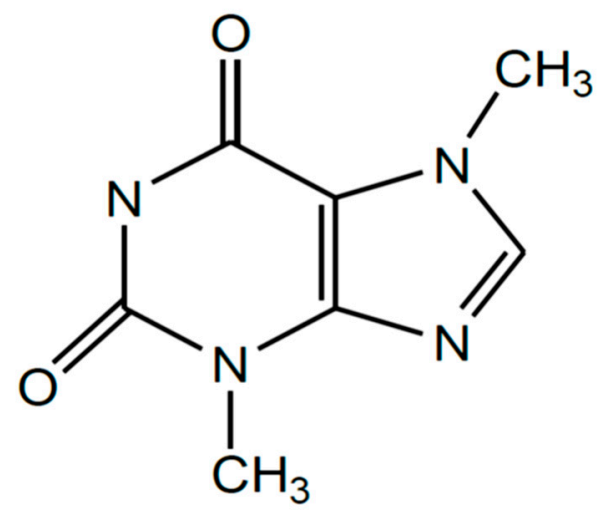

Figure 1. Chemical structure of theobromine [4].

As of late, few studies on cacao residues have been performed. For example, Arlorio et al. [5] reported that cacao bean hull, principal by-product from cacao industry, was commonly used as a secondary source of theobromine (1.29 g/100 $\mathrm{g}$ by dry weight), while Hammerstone and Chimel [6] extracted theobromine from cacao solids using various solvents, including isopropanol, methanol, and ethanol at different temperatures and found that the highest theobromine content was obtained by ethanol at $50{ }^{\circ} \mathrm{C}$. Peralta-Jiménez and Cañizares-Macías [7] also used an ultrasound-assisted method with heated water at $80{ }^{\circ} \mathrm{C}$ for the extraction of theobromine and caffeine from cacao seeds and chocolate products, and indicated that the extraction efficiency of theobromine from cacao seeds and chocolate products increased $43.6 \%$ and $23 \%$, respectively, when compared to conventional stirring extraction methods. Munier and Hartadi [8] reported that fresh cacao pod husk contained $0.40 \%$ theobromine and it was greatly reduced during fermentation by A. oryzae, and Adamafio [9] mentioned theobromine toxicity, theobromine catabolism, and de-theobromine methods from cacao by-products.

With regard to extraction and purification processes of bioactive compounds, water or organic solvent, or a mixture of water and organic solvent, has been used to extract xanthine alkaloids, such as caffeine and theobromine [3,10], while bleaching earth and activated carbon are usually used to remove foreign matter in water and oils [11,12]. However, the study on the proximate composition of cacao pod husk and optimal conditions for extraction and purification of theobromine from cacao pod husk has not been sufficiently reported. Therefore, this study aimed to determine the proximate composition of cacao pod husk, as well as optimal conditions for extraction and purification of theobromine from cacao pod husk as an abundant, inexpensive, renewable, and sustainable source using a non-toxic, accessible, and cheap solvent for potential application in the nutraceutical, medical, and pharmaceutical industries.

\section{Materials and Methods}

\subsection{Plant Material}

Twenty kilograms of cacao pods (Theobroma cacao trinitario) were purchased from the Western Highlands Agriculture and Forestry Science Institute, Buon Ma Thuot city, Dak Lak province, Vietnam (latitude $12.6667^{\circ} \mathrm{N}$, longtitude $108.0500^{\circ} \mathrm{E}$ ). After collection, cacao pods were packed in jute bags and immediately taken to the laboratory at Nha Trang University for further treatments. The fresh samples were then stored in the freezer at $-20^{\circ} \mathrm{C}$ until used for further experiments. The overall experimental procedure is described in Figure 2. 


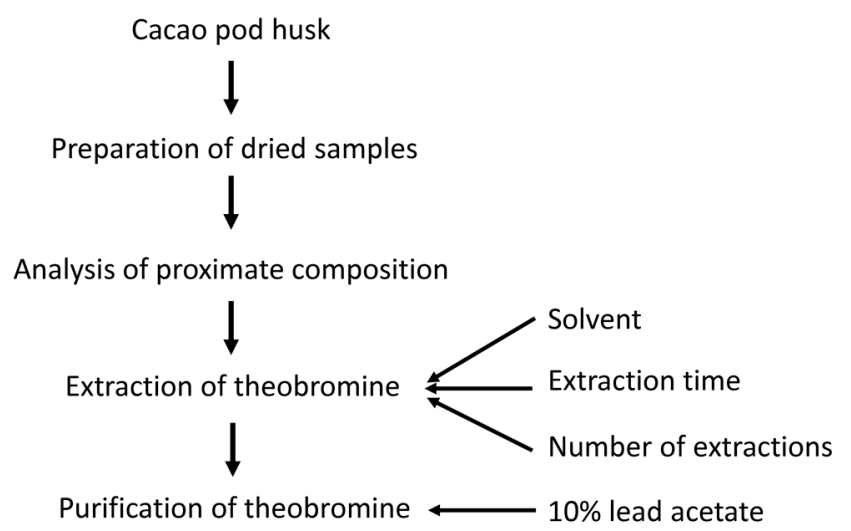

Figure 2. Overall experimental procedure of the study.

\subsection{Chemicals}

All chemicals used in this research were of analytical grade. Standard theobromine (purity 98.5\%) was purchased from Sigma-Aldrich Pte Ltd. (Nucleos, Singapore). Absolute ethanol, chloroform, acetonitrile, phosphoric acid, lead acetate, and sodium sulfate were purchased from the Chemical and Scientific Technological Join Stock Company (Ho Chi Minh City, Vietnam).

\subsection{Preparation of Dried Samples}

Fresh cacao pod husk was separated from cacao pods, then cut into small pieces, and dried at $45{ }^{\circ} \mathrm{C}$ to constant weight using an infrared drying cabinet (SHN-L, Nha Trang University, Vietnam) based on the formerly reported method of Nguyen et al. [13]. The dried samples were packed in sealed plastic bags and stored in a dry place until required. Prior to use for all experiments, the dried samples were ground to fine particles using a hammer mill [14].

\subsection{Analysis of Proximate Composition of Cacao Pod Husk}

The moisture, crude protein, crude lipid and ash contents of cacao pod husk were analyzed according to the Association of Official Analytical Chemists (AOAC) official method (1998) and based on the previously-described method by Nguyen [2]. Moisture content was determined using a hot-air oven at $100{ }^{\circ} \mathrm{C}$ overnight. Nitrogen content was measured using the Kjeldahl method and the crude protein content was then calculated by multiplying nitrogen content by a factor of 6.25 . Crude lipids were extracted using the Soxhlet method and the crude lipid content was determined after oven-drying the extract at $100^{\circ} \mathrm{C}$ for $30 \mathrm{~min}$. Ash content was measured by heating the cacao pod shells in a furnace at $600{ }^{\circ} \mathrm{C}$ for $5 \mathrm{~h}$. Carbohydrates (include crude fiber) was calculated from Equations (1) and (2) [15] as follows:

Carbohydrate $(\%$ by fresh weight $)=100-$ moisture - crude protein - crude lipid - ash

$$
\text { Carbohydrate }(\% \text { by dry weight })=100-\text { crude protein }- \text { crude lipid }- \text { ash }
$$

\subsection{Extraction of Theobromine from Cacao Pod Husk}

The extracts from cacao pod husk were prepared according to the prior methods of Nguyen [2] with some minor modifications. Briefly, to select the most effective solvent, $10 \mathrm{~g}$ of dried cacao pod husk was extracted with $270 \mathrm{~mL}$ of various solvents for $30 \mathrm{~min}$ at temperatures of $100{ }^{\circ} \mathrm{C}, 80^{\circ} \mathrm{C}$, and $60{ }^{\circ} \mathrm{C}$ for water, $70 \%$ ethanol and chloroform, respectively, using a Memmert WB29 thermostatic bath (Memmert GmbH + Co.KG, Schwabach, Germany), which was closely covered by a lid to avoid water evaporation during extraction. Different extraction times and the number of extractions were then applied with selected solvent to identify optimal extraction time and number of extractions. 
After extraction, the extracts were immediately cooled to room temperature using an ice water bath, and then filtered through a Whatman No. 1 filter paper to obtain the crude extracts for further analysis and experiments.

\subsection{Purification of Crude Extracts from Cacao Pod Husk}

Purification of the crude extracts from cacao pod husk containing theobromine is to remove foreign matters (protein, lipid, pectin, tannins, pigments, etc.) within the crude extracts for obtaining the pure extracts or theobromine-enriched extracts. Briefly, $10 \%$ lead acetate solution at different concentrations of $2.5 \%, 5.0 \%, 7.5 \%, 10.0 \%$, and $12.5 \%$ by volume was added to $40 \mathrm{~mL}$ of the crude extracts. The mixture was then left at room temperature $\left(32 \pm 2{ }^{\circ} \mathrm{C}\right)$ for $15 \mathrm{~min}$. After treatment with $10 \%$ lead acetate solution, the residual lead acetate in the extracts was completely removed by using $10 \%$ sodium sulfate solution (based on formation of white precipitate named as lead sulfate) and then filtered through a Whatman No. 1 filter paper to obtain the pure extracts. These pure extracts were then measured viscosity using a viscometer LVDV-E (Brookfield, NY, USA) at a speed of $60 \mathrm{rpm}$ and spindle S03, and absorbance at $436 \mathrm{~nm}$ using a Cary 50 UV-VIS spectrophotometer (Varian, Inc., Manasquan, $\mathrm{NJ}$, USA). The results of viscosity and absorbance at $436 \mathrm{~nm}$ were expressed as centipoise (cP) and absorbance unit, respectively. The best pure extract obtained after purification was also analyzed theobromine content to evaluate the effectiveness of the purification process.

\subsection{Analysis of Theobromine Content}

Theobromine content in the extracts from cacao pod husk was analyzed using HPLC system (Shimadzu, Kyoto, Japan) based on the previously developed method of Nguyen et al. [13] Briefly, the extracts and standard theobromine solution $(100 \mu \mathrm{g} / \mathrm{mL}$ in methanol) were filtered through $0.45 \mu \mathrm{m}$ nylon membranes, and $20 \mu \mathrm{L}$ were then individually injected by an auto injector (Shimadzu, Kyoto, Japan) onto a column $\mathrm{C}_{18}\left(250 \times 4.6 \mathrm{~mm} 5 \mu \mathrm{m}\right.$; Shimadzu, Kyoto, Japan), which was maintained at $35^{\circ} \mathrm{C}$ by a column oven (Shimadzu, Kyoto, Japan). The isocratic elution consisted of $0.05 \%$ phosphoric acid in distilled water (A) and 100\% acetonitrile (B) (85:15). Flow rate was set at $1 \mathrm{~mL} / \mathrm{min}$. The theobromine compound was detected at $272 \mathrm{~nm}$ using a UV-VIS detector (Shimadzu, Kyoto, Japan). Theobromine content in the extracts from cacao pod husk was quantified based on the calibration curve of standard theobromine by comparing retention time and peak area of standard theobromine with those in the extracts from cacao pod husk. The calibration curve of standard theobromine (concentration ranged from 0 to $5 \mathrm{mg} / \mathrm{L}$ ) is indicated in Figure 3. Limit of detection (LOD) and limit of quantification (LOQ) of standard theobromine were found to be 0.10 and $0.31 \mathrm{mg} / \mathrm{L}$, respectively.

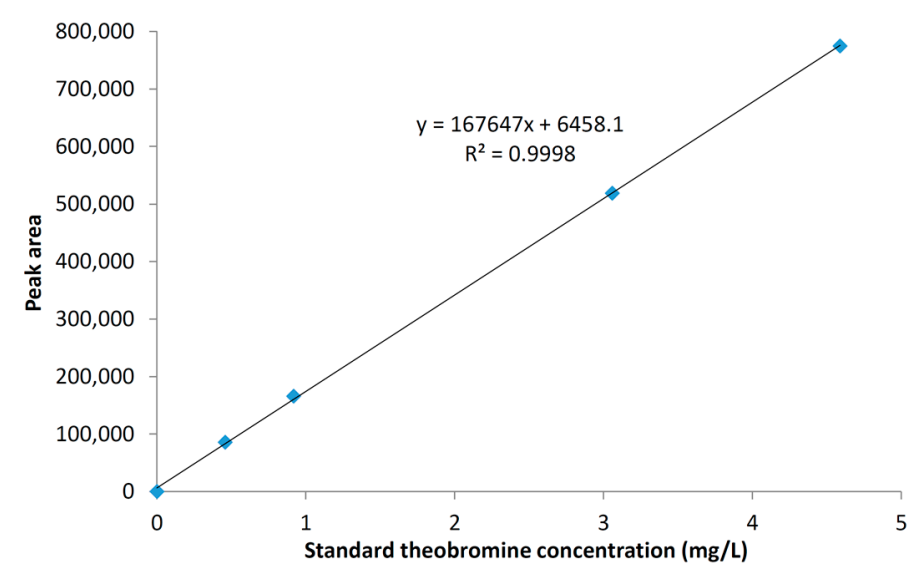

Figure 3. Calibration curve of standard theobromine. 


\subsection{Statistical Analysis}

All experiments were run in triplicate. The data were analyzed using SAS software (version 9.2, SAS Inst., Inc., Cary, NC, USA) and expressed as the mean \pm standard deviation $(n=3)$. Statistical comparisons were made using analysis of variance (ANOVA) and $t$-tests (LSD). Differences were considered significantly when $p$-values were below $0.05(p<0.05)$.

\section{Results and Discussion}

\subsection{Proximate Composition of Cacao Pod Husk}

The proximate composition of cacao pod husk was calculated based on fresh weight and dry weight (Table 1) to use for different purposes. The results showed that cacao pod husk had high contents of moisture and carbohydrates $(87.06 \%$ and $11.03 \%$ by fresh weight, respectively), but low contents of crude proteins, crude lipids, and ash $(0.31 \%, 0.12 \%$, and $1.48 \%$ by fresh weight, respectively). Based on dry weight, the contents of crude protein, crude lipid, ash, and carbohydrate were of $2.42 \%$, $0.93 \%, 11.44 \%$, and $85.21 \%$ by dry weight, respectively, indicating that cacao pod husk contains high carbohydrate content which forms a firm structure for its husk. The moisture content in cacao pod husk found in this study was similar to that in cacao pod shell $(87.0 \%)$, but the contents of crude protein, crude lipid, and ash in cacao pod husk were lower than those in cacao pod shell $(1.26 \%, 0.16 \%$, $2.30 \%$ by fresh weight and $9.69 \%, 1.23 \%$, and $17.69 \%$ by dry weight, respectively), and carbohydrate content in cacao pod husk was higher than that in cacao pod shell $(9.28 \%$ by fresh weight and $71.39 \%$ by dry weight, respectively) [2]. Marcel et al. [16] indicated that crude protein content in cacao pod shell, cacao pod husk, and cacao bean hull $(16.0 \%, 9.14 \%$, and $17.9 \%$ by dry weight, respectively) was much higher than that in cacao pod husk found in this study, whereas ash content in cacao pod shell, cacao pod husk and cacao bean hull $(7.5 \%, 9.07 \%$, and $9.3 \%$ by dry weight, respectively) was lower than that in cacao pod husk found in this study. Arlorio et al. [5] reported that moisture, the contents of crude lipid, crude protein and ash in pre-roasted cacao bean hull were of $10.12 \%, 6.81 \%, 18.12 \%$, and $8.1 \%$ by dry weight, respectively. These results showed that proximate composition in different parts of cacao pod was greatly different that directly relates to structural characteristics of cacao pod, in that cacao pod husk is a main part against insects and harmful effects from the environment in terms of physical, chemical, and microbial agents.

Table 1. Proximate composition of cacao pod husk.

\begin{tabular}{ccc}
\hline Proximate Composition & Fresh Weight (\%) & Dry Weight (\%) \\
\hline Moisture & $87.06 \pm 0.58^{*}$ & - \\
Crude protein (protein factor: 6.25$)$ & $0.31 \pm 0.21$ & $2.42 \pm 0.37$ \\
Crude lipid & $0.12 \pm 0.12$ & $0.93 \pm 0.34$ \\
Ash & $1.48 \pm 0.31$ & $11.44 \pm 0.41$ \\
Carbohydrate (include crude fiber) & $11.03 \pm 0.21$ & $85.21 \pm 0.29$ \\
\hline
\end{tabular}

* Means and standard deviations were of triplicate.

\subsection{Effect of Extraction Conditions on Theobromine Content from Cacao Pod Husk}

\subsubsection{Effect of Various Solvents on Theobromine Content}

Theobromine has been known as the most valuable compound in cacao and cacao products. Figure 4 illustrates HPLC chromatograms of standard theobromine (Figure 4A) and theobromine in the crude extract from cacao pod husk (Figure 4B). Theobromine content from cacao pod husk extracted by various solvents is indicated in Figure 5.

Among three solvents tested, $70 \%$ ethanol obtained the greatest level of theobromine ( $2.23 \mathrm{mg} / 100 \mathrm{~g}$ dry weight) as compared to those extracted by water and chloroform (0.09 and $0.35 \mathrm{mg} / 100 \mathrm{~g}$ dry weight), revealing that theobromine had a limited dissolvability in water, which 
is considered as a "green" solvent. This greatly related to the intermediate polarity of $70 \%$ ethanol, which allows it to solvate theobromine with low molecular weight containing functional groups $(-\mathrm{C}=\mathrm{O}$ and $-\mathrm{CH}_{3}$ ) [17]. Hu et al. [10] reported that $95 \%$ theobromine and $99 \%$ caffeine could be recovered by using a chloroform-water system, while Kasabe and Badhe [4] recovered theobromine in tea samples using various organic solvents and aqueous mixtures and found that an increase of recovery in order by $n$-hexane, ethyl acetate, methylene dichloride, chloroform, methanol, water, $5 \%$ sulphuric acid in water, and $5 \%$ diethyl amine in water, with a maximum level of theobromine was found to be $2.31 \%$ by dry weight. This data illustrated that the extractability of theobromine was greatly affected by the character of the solvent.
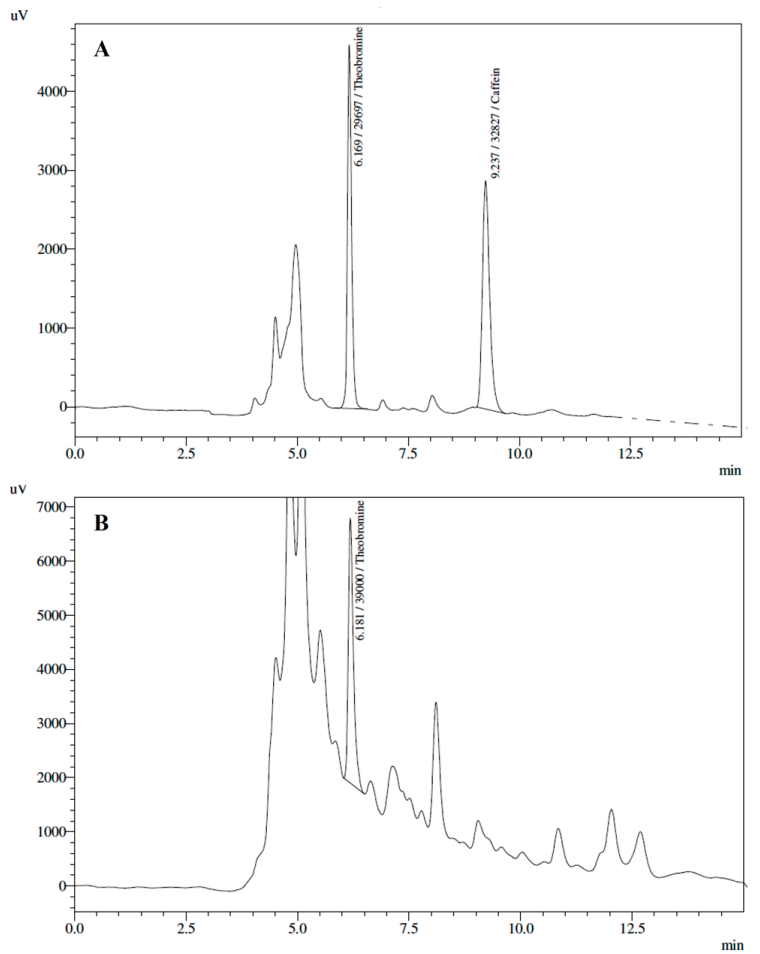

Figure 4. HPLC chromatograms of standard theobromine (A) and theobromine in the crude extract from cacao pod husk (B).

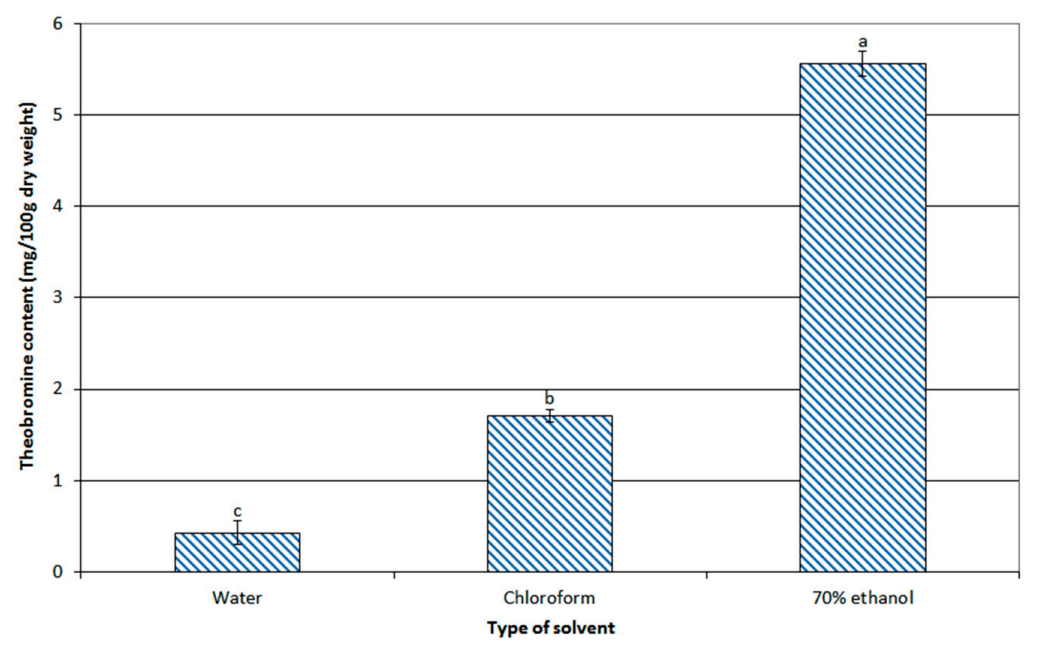

Figure 5. Effect of solvents on theobromine content from cacao pod husk. Different letters $(a, b, c)$ indicated significant differences between treatments $(p<0.05)$. 
Of these, $70 \%$ ethanol was selected for further extraction of theobromine from cacao pod husk, which is inexpensive, accessible, and friendly to humans and the environment.

\subsubsection{Effect of Extraction Time and Number of Extractions on Theobromine Content}

Figure 6 indicates the effect of different extraction times and number of extractions on theobromine content from cacao pod husk. Of which, theobromine content was significantly higher when cacao pod husk was extracted by $70 \%$ ethanol at longer times $(2.23 \%, 3.29 \%$, and $5.98 \mathrm{mg} / 100 \mathrm{~g}$ dry weight for 30, 60, and $90 \mathrm{~min}$, respectively). However, theobromine content was not significantly different when number of extractions increased from 1 time to 2 times $(5.98$ and $6.06 \mathrm{mg} / 100 \mathrm{~g}$ dry weight, respectively). This finding is supported by Nguyen and Pham [14] and Nguyen [2] who reported that the extract concentration from different parts of artichoke plant (leaf, stalk, root, and flower) and pigment yield from cacao pod shell attained an equilibrium at extraction times of 60 and $80 \mathrm{~min}$, respectively, and Tan et al. [18] also found that and the phenolic extraction efficiency from bitter melon was not significantly different after an extraction time of $5 \mathrm{~min}$ and one extraction. Considering the production costs, longer extraction times and more number of extractions consume more energy for extraction and remove solvent after extraction, leading to higher production costs, this is an important factor and needs to be properly considered when selecting extraction time and number of extractions. Therefore, an extraction time of $90 \mathrm{~min}$ and one as the number of extractions were suitable for extraction of theobromine from cacao pod husk.

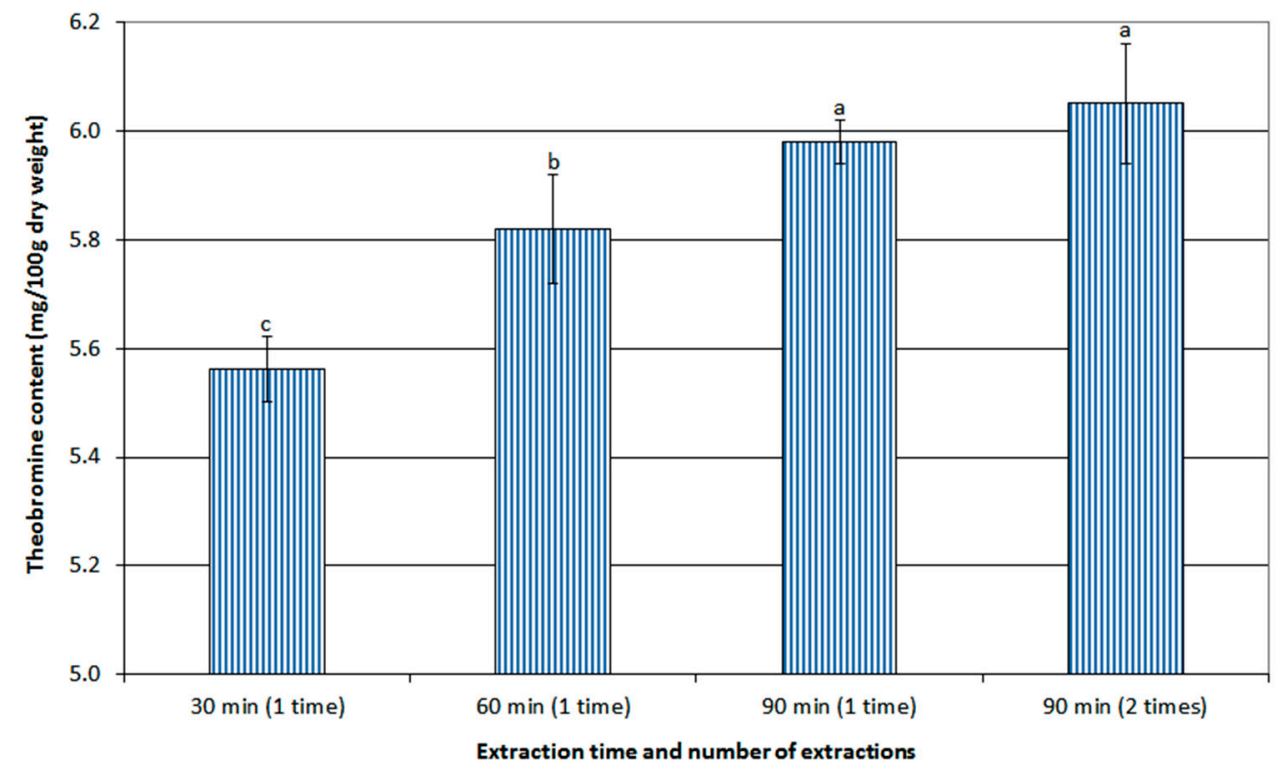

Figure 6. Effect of different extraction times and number of extractions on theobromine content from cacao pod husk. Different letters $(a, b, c)$ indicated significant differences between treatments $(p<0.05)$.

\subsection{Effect of Purification on Physicochemical Properties of Extracts and Theobromine Content from Cacao} Pod Husk

In this study, lead acetate was used as an agent to remove foreign matter within the crude extracts from cacao pod husk including protein, lipid, pectin, tannins, pigments, and so on due to bleaching earth and activated carbon could absorb greatly theobromine in the extracts, leading to the loss of theobromine. The effect of $10 \%$ lead acetate solution concentration on the viscosity and absorbance of the extracts from cacao pod husk is shown in Figure 7. In this instance, the viscosity of the extracts was significantly reduced at a concentration of $2.5 \%$ by volume of $10 \%$ lead acetate solution (4.77 to $3.90 \mathrm{cP}$ ), but no significant difference in the absorbance of the extracts was observed (1.87 and 1.83 absorbance units). However, when the concentration of $10 \%$ lead acetate solution increased from 
$2.5 \%$ to $5.0 \%$ by volume, both the viscosity and absorbance of the extracts were significantly decreased (3.90 to $3.63 \mathrm{cP}$ and 1.83 to 0.37 absorbance unit, respectively), and then they were significantly reduced with an increase of the concentration of $10 \%$ lead acetate solution from $5.0 \%$ to $7.5 \%$ by volume ( 3.63 to $3.54 \mathrm{cP}$ and 0.37 to 0.30 absorbance units, respectively). The absorbance of the extracts was continuously reduced when the concentration of $10 \%$ lead acetate solution rose from $7.5 \%$ to $10.0 \%$ by volume, whereas the viscosity of the extracts was not significantly different. These results indicated that the concentration of $10.0 \%$ by volume of $10 \%$ lead acetate solution was the best selection for purification of the extracts from cacao pod husk. Under the extraction conditions of $70 \%$ ethanol, one extraction for $90 \mathrm{~min}$, and purification with a concentration of $10.0 \%$ by volume of $10 \%$ lead acetate solution, theobromine content achieved $6.79 \mathrm{mg} / 100 \mathrm{~g}$ dry weight, which was higher than that without purifying by $10 \%$ lead acetate solution $(5.58 \mathrm{mg} / 100 \mathrm{~g}$ dry weight). This is due to the effect of foreign matter present in the extracts, leading to a decrease in the detectability of theobromine in the extracts by HPLC analysis. Howlader et al. [19] and Reddy and Lakshmi [20] also used 10\% lead acetate solution as an agent to detect the presence of tannins in the methanolic extract from Diospyros blancoi leaf and phenolic compounds in the extract from the whole plant of Oxalis corniculata L, based on the formation of white precipitate in the end-products.

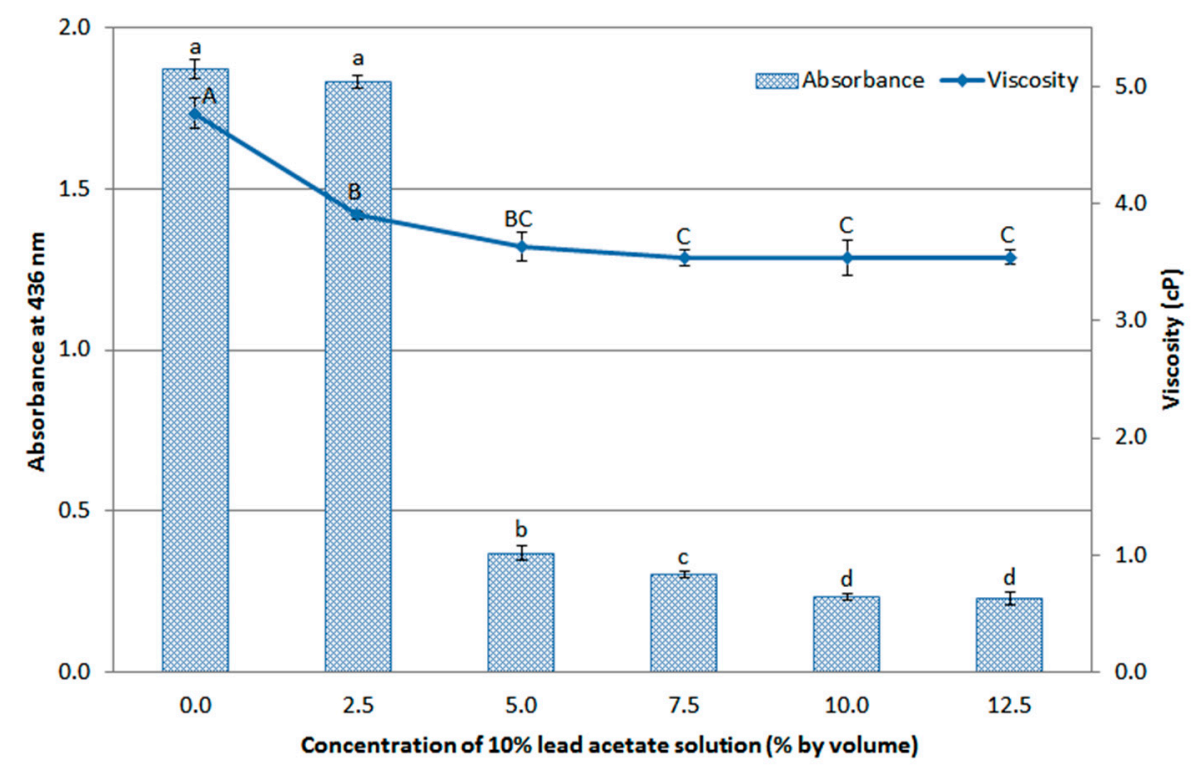

Figure 7. Effect of concentration of $10 \%$ lead acetate solution on viscosity and absorbance of the extracts from cacao pod husk. Different letters ( $a, b, c, d, A, B, B C, C)$ indicated significant differences between treatments $(p<0.05)$.

By applying the conventional extraction technique in this study, theobromine content obtained from cacao pod husk was lower than that found in cacao bean hull (1.29 g/100 g dry weight) [5] and in tea samples ( $2.31 \mathrm{~g} / 100 \mathrm{~g}$ dry weight) [4]. This outcome revealed that although theobromine content in cacao pod husk is lower than that in some other materials, a very large amount of cacao pod husk is discarded from the cacao processing industry, approximately 55 million tonnes per year. Therefore, cacao pod husk is an inexpensive, renewable, and sustainable source for extraction of theobromine, with an estimation about 457.1 tonnes per year. To increase the extraction efficiency of theobromine and reduce extraction time, further research can be applied some advanced extraction techniques, such as ultrasound-assisted extraction [17], microwave-assisted extraction [21], and supercritical fluid extraction [22]. 


\section{Conclusions}

This study was an exploratory and valuable assessment for further studies. The findings from this study indicated that cacao pod husk had high contents of moisture and carbohydrates, but low contents of crude protein, crude lipid, and ash. The extraction and purification processes greatly influenced on theobromine content from cacao pod husk, particularly solvent, extraction time, and concentration of $10 \%$ lead acetate solution. Therefore, the use of these extraction and purification conditions for effective exploitation of theobromine from cacao pod husk is a promising and sustainable trend. In further studies, it is necessary to determine the biological variability of theobromine in cacao pod husk samples, as well as produce theobromine-enriched powder and evaluate its biological activity in various models for potential application in the medical and pharmaceutical industries.

Acknowledgments: We sincerely acknowledge Nha Trang University, Vietnam for financial and mechanical support. The authors also would like to kindly thank Huu Tuan Nguyen and Thi Be Phan for their experimental support.

Author Contributions: Van Tang Nguyen conceived and designed the experiments, performed the experiments, analyzed the data, and wrote the paper. Nghia Huu Nguyen reviewed and suggested the paper.

Conflicts of Interest: The authors declare no conflict of interest.

\section{References}

1. FAOSTAT. FAO Statistic Division. Food and Agriculture Organization of the United Nations. Available online: http:/ / faostat3.fao.org/home/E (accessed on 31 December 2015).

2. Nguyen, V.T. Mass proportion, proximate composition and effects of solvents and extraction parameters on pigment yield from cacao pod shell (Theobroma cacao L.). J. Food Process. Preserv. 2014, 39, 1414-1420. [CrossRef]

3. De Sena, A.R.; de Assis, S.A.; Branco, A. Analysis of theobromine and related compounds by reversed phase high-performance liquid chromatography with ultraviolet detection: An update (1992-2011). Food Technol. Biotechnol. 2011, 49, 413-423.

4. Kasabe, A.J.; Badhe, G.B. Extraction and estimation of theobromine in marketed tea by HPTLC and UV method. Int. J. Appl. Biol. Pharm. Technol. 2010, 1, 367-373.

5. Arlorio, M.; Coisson, J.; Travaglia, F.; Varsaldi, F.; Miglio, G.; Lombardi, G.; Martelli, A. Antioxidant and biological activity of phenolic pigments from Theobroma cacao hulls extracted with supercritical $\mathrm{CO}_{2}$. Food Res. Int. 2005, 38, 1009-1014. [CrossRef]

6. Hammerstone, J.; Chimel, M. Methods for Extracting Cocoa Procyanidins and Extracts Thereof. U.S. Patent 0309991 A1, 17 August 2012.

7. Peralta-Jiménez, L.; Cañizares-Macías, M. Ultrasound-assisted method for extraction of theobromine and caffeine from cacao seeds and chocolate products. Food Biol. Technol. 2013, 6, 522-3529. [CrossRef]

8. Munier, F.; Hartadi, H. Theobromine content in cocoa pod husk (Theobroma cacao) fermented by Aspergillus spp. in different of chop sizes and fermentation times. In Proceedings of the 2nd International Seminar on Animal Industry, Jakarta, Indonesia, 5-6 July 2012.

9. Adamafio, A. Theobromine toxicity and remendiation of cacao by-products: An overview. J. Biol. Sci. 2013, 13, 570-576.

10. Hu, X.; Wan, X.; Bal, R.; Yang, H. Theobromine and caffeine recovery with solvent extraction. Sep. Sci. Technol. 2003, 38, 3609-3624. [CrossRef]

11. Jurado-Sánchez, B.; Sattayasamitsathit, S.; Gao, W.; Santos, L.; Fedorak, Y.; Singh, V.V.; Orozco, J.; Galarnyk, M.; Wang, J. Self-propelled activated carbon janus micromotors for efficient water purification. Small 2015, 11, 499-506. [CrossRef] [PubMed]

12. David, D.B.; Roberto, B.; Allan, S.H. Optimization of Bleaching Process in Edible Oil Processing. AOCS Lipid Library. Available online: http://lipidlibrary.aocs.org/OilsFats/content.cfm?ItemNumber=40321 (accessed on 8 June 2016).

13. Nguyen, V.T.; Vuong, Q.V.; Bowyer, M.C.; van Altena, I.A.; Scarlett, C.J. Effects of different drying methods on bioactive compound yield and antioxidant capacity of Phyllanthus amarus. Dry. Technol. J. 2015, 33, 1006-1017. [CrossRef] 
14. Nguyen, V.T.; Pham, Q.T. Effect of raw material and processing factors on the production of effervescent artichoke (Cynara scolymus L.) tea tablets. Int. J. Food Eng. 2011, 7, 1-17. [CrossRef]

15. Nguyen, V.T.; Ueng, J.P.; Tsai, G.J. Proximate composition, total phenolic content, and antioxidant activity of Seagrape (Caulerpa lentillifera). J. Food Sci. 2011, 76, C950-C958. [CrossRef] [PubMed]

16. Marcel, B.K.G.; Andre, K.B.; Theodore, D.; Eeraphin, K.C. Waste and by-products of cocoa in breeding: Research synthesis. Int. J. Agron. Agric. Res. 2011, 1, 9-19.

17. Nguyen, V.T.; Bowyer, M.C.; Vuong, Q.V.; van Altena, I.A.; Scarlett, C.J. Phytochemicals and antioxidant capacity of Xao tam phan (Paramignya trimera) root as affected by various solvents and extraction methods. Ind. Crops Prod. 2015, 67, 192-200. [CrossRef]

18. Tan, S.P.; Stathopoulos, C.; Parks, S.; Roach, P. An optimised aqueous extract of phenolic compounds from bitter melon with high antioxidant capacity. Antioxidants 2014, 3, 814-829. [CrossRef] [PubMed]

19. Howlader, S.I.; Rahman, M.; Khalipha, A.B.R.; Rahman, M.; Ahmed, F. Antioxidant and antidiarrhoeal potentiality of Diospyros blancoi. Int. J. Pharmacol. 2012, 8, 403-409.

20. Reddy, K.Y.; Lakshmi, S.M. Pharmacognostical and phytochemical investigation of whole plant of Oxalis corniculata L. Int. J. Phytother. 2012, 2, 34-53.

21. Nguyen, V.T.; Pham, H.N.T.; Bowyer, M.C.; van Altena, I.A.; Scarlett, C.J. Influence of solvents and novel extraction methods on bioactive compounds and antioxidant capacity of Phyllanthus amarus. Chem. Pap. 2016, 70, 556-566. [CrossRef]

22. Wozniak, L.; Marszalek, K.; Skapska, S. Extraction of phenolic compounds from sour cherry pomace with supercritical carbon dioxide: Impact of process parameters on the composition and antioxidant properties of extracts. Sep. Sci. Technol. 2016, 51, 1472-1479. [CrossRef]

(C) 2017 by the authors. Licensee MDPI, Basel, Switzerland. This article is an open access article distributed under the terms and conditions of the Creative Commons Attribution (CC BY) license (http:/ / creativecommons.org/licenses/by/4.0/). 